\title{
Influence of Religiosity on the Quality of Life and on Pain Intensity in Chronic Pancreatitis Patients After Neurolytic Celiac Plexus Block: Case-Controlled Study
}

\author{
Andrzej Basiński • Tomasz Stefaniak • Magdalena Stadnyk • \\ Arfan Sheikh • Ad J. J. M. Vingerhoets
}

Published online: 1 February 2011

(C) The Author(s) 2011. This article is published with open access at Springerlink.com

\begin{abstract}
The quality of life in patients with chronic pancreatitis (CP) is reduced due to their suffering of high levels of pain. It has been presented that quality of life can also be linked to religiosity and/or spirituality. The aim of this study is to assess the influence of religious practices on the quality of life and on the subjective level of pain in CP patients. Ninety-two patients (37 women and 55 men) with chronic pancreatitis were treated invasively for pain with neurolytic celiac plexus block (NCPB). The religiosity of the patients was recorded and served as a dichotomizer. Group 1 was for patients who claimed to have no contact with the church or to have very sporadic contact ( $N=35$ patients). Group 2 was for patients who claimed to have deep faith and were regular participants at church activities ( $N=57$ patients). Visual analogue scale was used to assess pain, while the quality of life was measured by using QLQ C-30 questionnaire adapted for chronic pancreatitis patients in Polish population. The patients were assessed prior to the painrelieving intervention and subsequently 2 and 8 weeks after it. The intensity of pain was reduced in both groups significantly after performing the NCPB. Patients who declared a deep faith reported higher level of pain on the VAS scale prior to intervention than nonreligious patients. Quality of life in both groups of patients significantly improved after NCPB. Following NCPB, global quality of life in patients who declared higher religiosity/ church attendance was significantly higher (79.88) than for those patients who have no contact or sporadic contact with the church $(44.21, P<0.05)$. NCPB resulted in significant
\end{abstract}

\footnotetext{
A. Basiński

Department of Emergency Medicine, Medical University of Gdansk, Gdansk, Poland

T. Stefaniak $(\bowtie) \cdot$ A. Sheikh

Department of General, Endocrine and Transplant Surgery, Medical University of Gdansk,

7 Debinki Str., PL-80-210 Gdansk, Poland

e-mail: wujstef@gumed.edu.pl
}

T. Stefaniak $\cdot$ M. Stadnyk

Laboratory of Psychology of Surgery and Psychosomatics, Department of General,

Endocrine and Transplant Surgery, Medical University of Gdansk, Gdansk, Poland

\author{
A. J. J. M. Vingerhoets \\ Department of Clinical Psychology, Tilburg University, Tilburg, The Netherlands
}


reduction of pain and increase in quality of life in both groups of patients with $\mathrm{CP}$. Nevertheless, in the group declaring higher religiosity/church attendance, reported pain was higher, but, despite that, quality of life better. It may be concluded that religious practices might serve as an additional factor improving quality of life and coping in patients suffering from chronic pancreatitis.

Keywords Chronic pancreatitis · Pain · Coping - Religiosity ·

Neurolytic coeliac plexus block $\cdot$ NCPB $\cdot$ Spirituality

\section{Introduction}

Thanks to progress in modern medicine and the latest development in technology, it has been possible to employ advanced methods for the diagnostics and therapeutics to prolong the average human life-span. In 1900, for both men and women, it averaged 48 years, in 1960-50 years and in 2000 it reached 66.7 years. Nevertheless, behind this apparent success, there is another dimension. Acute illnesses have given way to chronic ones as the main source of suffering, and this has led to a decrease in the global quality of life, effectiveness and functionality of patients, with pain being the most debilitating and predominant cause for such a phenomenon.

Chronic pancreatitis (CP) is a disease with a long course, which leads to a gradual degradation of internal and external functioning of the pancreas. Very often, it is accompanied by strong pain that can only be effectively treated by the chronic use of opioids (Ballantyne 2006) and significantly impairs all domains of the quality of life (Ballantyne 2006; McCarberg and Billington 2006). Considerably, aggressive conservative treatment with eager use of opioids may further lead to diminishing of quality of life of the patients, predominantly in the aspects of social life and everyday functioning (Ruetsch 2010). That fact should be carefully considered in light of the long-term survival of CP patients (Stefaniak et al. 2008) and subsequently, the necessity for long-term opioid therapy and increased risk of iatrogenic opioid addiction (Nishimori et al. 2006; Ruetsch 2010). Therefore, apart from conservative pain treatment utilised in chronic pancreatitis, special attention must be given to invasive methods like neurolytic celiac plexus block (NCPB), and thoracoscopic splanchnicectomy (TS) that provide a chance for reduction of intensity of conservative treatment and/or prolonging the effectiveness of the drugs instituted and prevention of fast drug dose escalation (Basinski et al. 2005; Stefaniak et al. 2005). It has been previously documented that both NCPB and TS significantly reduce levels of pain and help to improve the quality of life in chronic pancreatitis patients (Basinski et al. 2005; Makarewicz et al. 2003). The first is a minimally invasive, transcutaneous puncture technique that temporarily destroys passage of pain impulses to brain and also provides information on effectiveness of this path of therapy, before making a decision about performing a splanchnicectomy, which surgically removed part of this passage (Basinski et al. 2005; Stefaniak et al. 2005).

Many previous studies have shown the influence of spirituality and religion on both health and quality of life. Religiosity is an understanding and involvement in a system of beliefs and practices, whereas spirituality is a search for the meaning of life and holiness and does not necessarily lead to the religiosity. It is currently considered similar to church/ religious meeting attendance and potentially opposed to spirituality. Spirituality is a very individual experience, whereas religion entails a sharing of beliefs and rituals with community (King and Koenig 2009). It is a recent review by Visser et al. (2010), and it has 
been presented that high spirituality leads to significant improvement of quality of life in various cancer diseases. It has also been presented by Giovagnoli et al. (2006) that religiosity may provide similar improvement of quality of life in epilepsy. Harrison et al. (2005) postulated that religiosity is positively connected with the level of global health. Moreover, Sloan et al. (1999) have demonstrated that religion and praying can lead to a faster recovery in various diseases, while Koening et al. (2009) have shown that spirituality and religion can be influencing such physiological parameters as cardiovascular and immune system leading to lower blood pressure, improved resistance to illness and lipid profile.

Religion is considered to serve 3 purposes for patients. First, as a base to find the meaning of illness, second to provide the resources for coping and finally to improve or to provide hope. This leads to a better coping with illness and avoidance of destructive behaviours. Additionally, faith and practicing of religion are connected with lower anxiety levels, reduced incidences of depression and lower level of stress and even decreased number of suicides (Seeman, Dubin, and Seeman 2003; Weaver and Koenig 2006).

Spiritual practice has also a significant influence on emotion and mental health, contributes to increased levels of self control and to diminished levels of frustration (Boelens et al. 2009; Bussing et al. 2009; Weaver and Koenig 2006). In patients suffering from chronic disease such as $\mathrm{CP}$, positive relationship between QoL and spirituality/religiosity may be expected, that is, increased level of spirituality and/or religiosity would correlate with a higher level of quality of life.

The main aim of this study is to assess for the first time in worldwide literature the influence of religiosity on quality of life and on the pain levels of chronic pancreatitis patients suffering from chronic pain.

\section{Methods}

\section{Patients}

There were 92 patients with chronic pancreatitis suffering from pain participated in this study. Patients were treated in the period of 2004-2008 at the Medical University of Gdansk. Epidemiological data of the participants are presented in Table 1.

Neurolytic celiac plexus block was performed in all patients. The indication for this procedure was intense pain above 7 in the 10-degree VAS pain scale, independent from pharmacological treatment. Neurolytic celiac plexus block was performed by using the classical method, as described by Kappis (Stefaniak et al. 2005).

After performing the neurolytic celiac plexus block for all 92 patients, the patients were ex post separated into two groups. Group 1 included patients who claimed to have no contact with the church or to have very sporadic contact. Group 2 included patients who claimed to be religious and were regular participants at church mass (all of them were

Table 1 Epidemiological data of patients with chronic pancreatitis, treated with neurolytic celiac plexus block

\begin{tabular}{lll}
\hline Gender & $\begin{array}{l}\text { Number } \\
\text { of patients }\end{array}$ & $\begin{array}{l}\text { Average age } \\
\text { (years) }\end{array}$ \\
\hline Female & 37 & $48 \pm 4.0$ \\
Male & 55 & $50 \pm 5.0$ \\
\hline
\end{tabular}


Roman Catholics). Thirty-five patients qualified for group 1 and 57 patients qualified for group 2. The patients did not differ in term of epidemiological parameters (Table 1).

\section{Measures}

Data were recorded for the level of pain suffering by using the 10-degree visual analogue scale (VAS). Patients evaluated their level of pain in the 3-day period before NCPB. Measurements were taken every $3 \mathrm{~h}$. After the procedure, patients continued to evaluate their level of pain every $3 \mathrm{~h}$ for 1 week and then once a day up to and including the 4th week. In the situation when the pain treatment required additionally support, pain was measured again every $3 \mathrm{~h}$. The type and dosage of medication used were recorded for all patients.

Quality of life was assessed using the well-validated EORTC quality of life questionnaire QLQ C-30, which was adapted for chronic pancreatitis in Polish conditions (Stefaniak et al. 2008). The questionnaire consists of 30 questions, and it is divided into two parts. First part focuses on functional parameters, and the second one concerns symptomatic parameters. The raw data generated by the questionnaire are then compared against a scale to get the final value. The scale ranges from 1 to 100 . High results in the functional parameter mean higher quality of life, whereas high results in the symptomatic parameter indicate higher intensity of symptoms. Patients completed the QLQ C-30 questionnaire $24 \mathrm{~h}$ before undergoing the neurolytic celiac plexus block and also on the 1st, 4th and 8th week in follow-up from the procedure. Before the patients were asked to complete the questionnaires, they were informed about the aim and purpose of the study.

Statistical analysis of the results contained calculation of the arithmetical average, standard deviation, minimum and maximum value, and the statistically significant difference between the groups was also assessed with the aid of $t$ test, ANOVA and Wilcoxon. The level of significance was calculated to be $P<0.05$. All analyses were performed using the computer programme STATISTIC 8.0PL licensed to the Medical University of Gdansk.

\section{Results}

The results of pain reduction due to NCPB are presented in Table 2. Immediately after performing the NCPB, the level of pain for patients in both groups was reduced. After the 1st week following the procedure, pain was decreased in both groups. After the 4th week, the values were still significantly lower than before the neurolytic block. During the 1st week after performing the neurolytic block, strong pain was reported by the patients in group 2, whereas after the 4th week, these values were similar for both groups.

Table 2 Average results of VAS pain scale assessment for patients with chronic pancreatitis

\begin{tabular}{llll}
\hline & Before the procedure & $\begin{array}{l}\text { 1 week after } \\
\text { the procedure }\end{array}$ & $\begin{array}{l}4 \text { weeks after } \\
\text { the procedure }\end{array}$ \\
\hline Group I & $7.62 \pm 0.89$ & $3.99 \pm 0.88^{*}$ & $3.28 \pm 0.38^{*}$ \\
Group II & $7.34 \pm 0.19$ & $4.12 \pm 0.32^{*}$ & $3.21 \pm 0.52^{*}$ \\
\hline
\end{tabular}

$* P<0.001$, post-hoc Scheffe test 


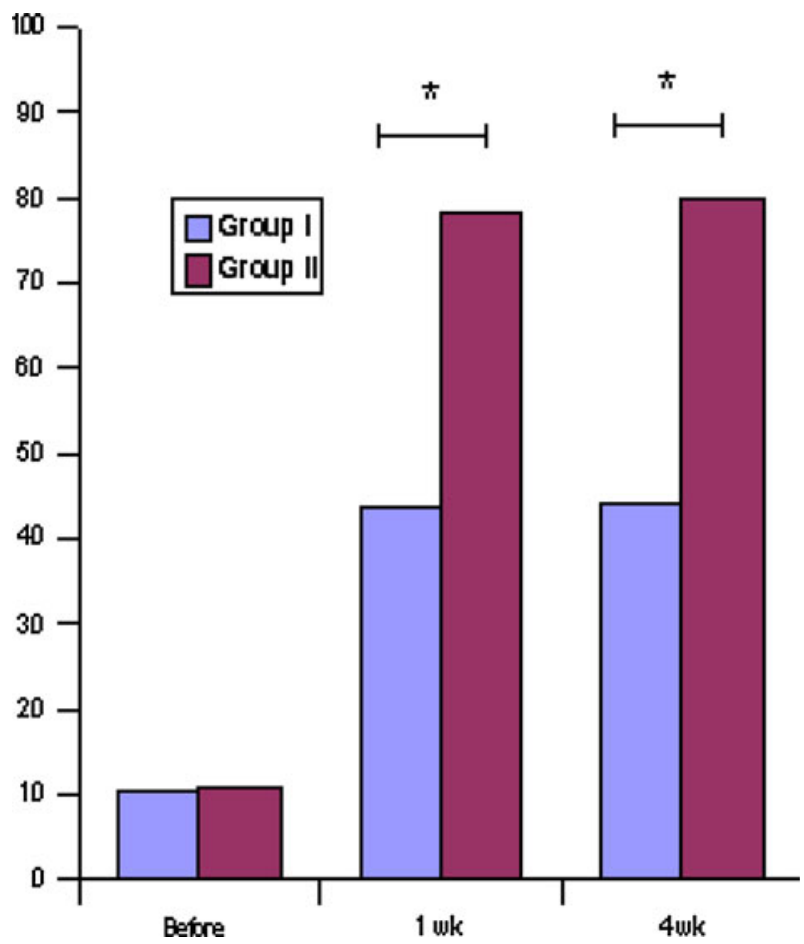

Fig. 1 Results of global quality of life in chronic pancreatic pain patients treated with neurolytic celiac plexus block (Group I-low religiosity, Group II-high religiosity). ${ }^{*} P<0.05$; test $t$ Student (ANOVA)

In literature, it is accepted for good and very good results of analgesic control to be below a value of 3 or less on the VAS pain scale. One week after performing the NCPB, the majority of patients were scoring between the levels of 4-5 on the VAS scale. Conversely, 4 weeks after performing the plexus block, majority of patients obtained good and very good reduction of pain. Both 1 and 4 weeks after the NCPB, patients from group 2 experienced more pain than patients from group 1 .

Quality of life of patients with chronic pancreatitis who were treated with neurolytic celiac plexus block significantly improved after the treatment. Quality of life scores are shown in Fig. 1.

In both groups, values of functional scale were significantly improved in all subscales after the NCPB. Values for social and cognition scales after NCPB were higher in group 1, whereas values in scales: work, efficiency and global quality of life were higher in group 2 (Fig. 2).

\section{Discussion}

In this research, for the first time in worldwide literature, we compared pain and quality of life in two different groups of chronic pancreatitis patients- those who declared no contact with the church or sporadic contact, and those who declared religiosity/church attendance. In both groups, the effectiveness of pain treatment was satisfactory. Interestingly, patients 

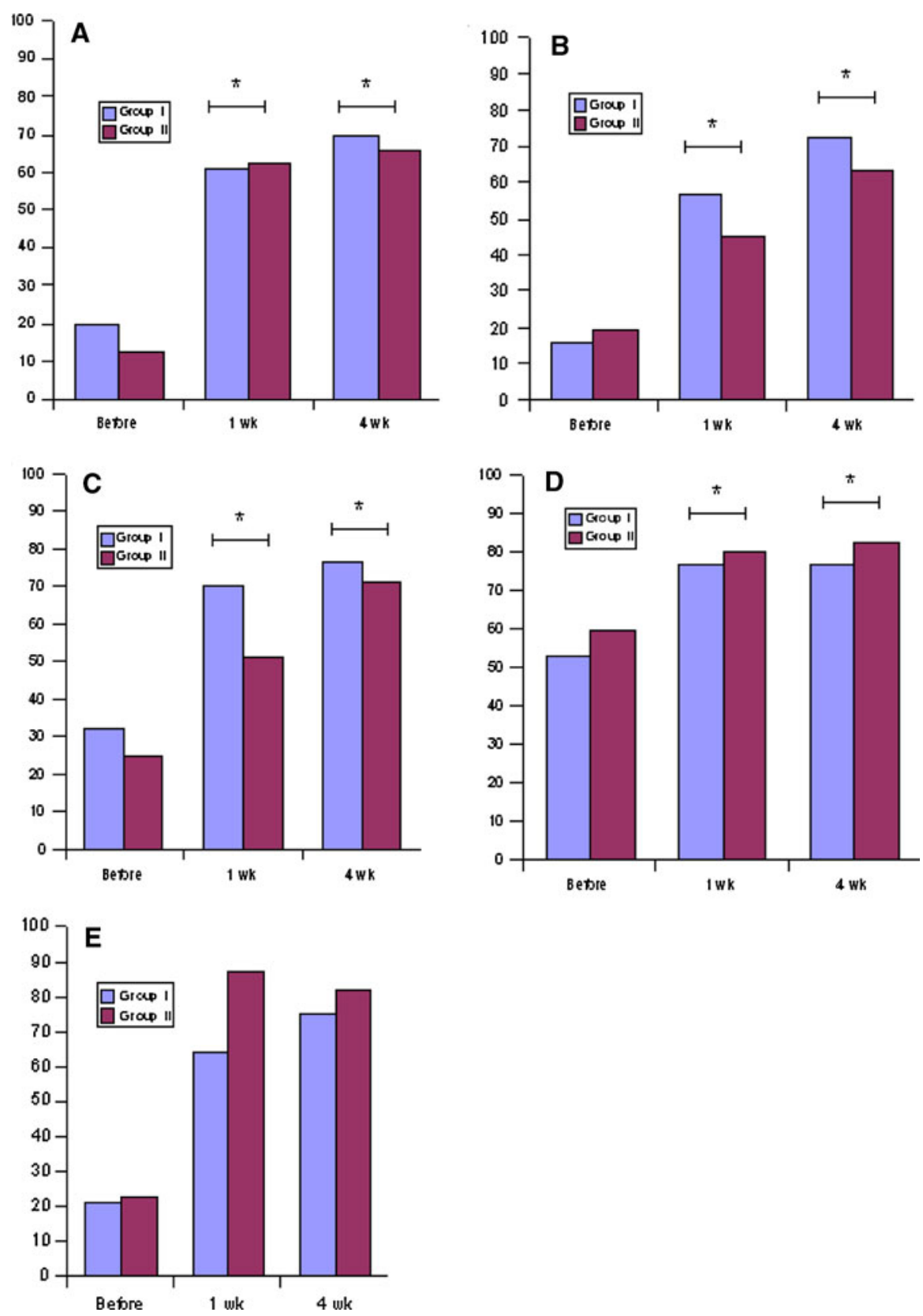

Fig. 2 QLQ-C30 subscales of functioning for patients treated with neurolytic celiac plexus block. a emotional, b social, $\mathbf{c}$ cognitive, $\mathbf{d}$ work, e efficiency. $P<0.05$, test $t$ Student (ANOVA)(Group I-low religiosity, Group II-high religiosity)

of higher religiosity/church attendance assessed their pain to be on a higher level on the VAS scale. McBride et al. (1998) has shown that the lowest pain is reported by those people who declared their faith to be of a medium level. On the other hand, Yates et al. 
(1981) have revealed by assessing 71 patients with advanced cancer that religious patients suffer from lower level of pain. Connection between religiosity and pain has also been shown by Harrison et al. In this research, 50 chronic pain patients were assessed for the following three parameters: frequency of visiting the church, frequency of praying and internal conviction of religiosity. It has been presented that going to church minimum once a week was strongly correlated with lower level of pain, whereas praying and internal conviction of faith had no effect on pain (Harrison et al. 2005). Similar effect was observed by Turner and Clancy who showed that chronic back pain patients, who prayed, experienced less intense pain (Bussing et al. 2009). Koening (2009) has also shown in his research a negative correlation between praying and level of pain. Yates et al. (1981) have also found that religious convictions can additionally influence the individual mood of the patients and in this way the perception of pain intensity can be altered. It has been shown that having strong religious beliefs can reduce sensitivity to pain. Similar results were presented in our study. In context of likely aetiology of CP (alcoholism), the religious patients may consider their suffering as a form of redemption and thus may be more likely to experience and report higher pain.

In quality of life part of our research, it was confirmed that improvement in quality of life can be caused by lower pain intensity, but also can be supported and potentiated by other factors such as religiosity. So, as presented previously (Basinski et al. 2005), invasive pain treatment such as NCPB or TS led to reduction of pain and, in consequence, to an improvement of quality of life.

In our research, we have shown that quality of life in chronic pancreatitis can be further influenced by the level of religiosity/church attendance. Global quality of life after NCPB was significantly higher in religious/more church attending patients than in these who had no contact or sporadic contact with church. It can be hypothesised that, despite reports of higher pain intensity, religious practice can help patients to cope better with chronic disease and broaden their network of social support (Visser et al. 2010). Patients, who have larger and more diversified resources for coping, are better prepared for illness and manage it better. They may also find sense in their suffering, hoping that it can lead to expiation and salvation. It has been explained that people may apply meaning to events taking place in their lives by integrating these events within the general scheme of how they arrange their world. This helps to perceive benefits with this event making better relationship within our close ones in disease situation (Moreira-Almeida et al. 2006). Additionally, under the influence of emotions, which are caused by both the event and the activity, patients may develop their own resources, which may lead to better coping to help overcome difficult situations (Seeman et al. 2003). People feeling positive emotions use strategies that focus on tasks and at the same time look for positive side of negative events (Koenig 2009), which may lead to better coping with illness or pain.

Bussing et al. have shown that many patients with chronic pain use religious practice to cope with pain. In the moment when pain increases in intensity, patients often engage in religious activity such as prayer (Bussing et al. 2009). Hill and Pargament distinguished two kinds of spiritual coping: (1) active, connected with solving problems by co-operating with God or helping others in need and (2) passive, which makes God responsible for the illness and for rejection and helplessness the patient experience (Hill and Pargament 2003). Active strategies are connected with positive affect (Bush et al. 1999), lower level of stress and greater "positive feedback" of spirituality, while passive ones lead to depression, loneliness and increased symptom perception (Tarakeshwar et al. 2006). In our study, the specific type of religiosity was not assessed, but as the quality of life improved despite higher pain, it may be assumed that most of the patients presented active type of spiritual 
coping. It is also typical for Catholic believers that God is not blamed for the problems approached by the patients, He is more likely to be seen as the saviour and "Good Father".

Strategies of coping, like spirituality can lead to changed perspective of situation and can result in better adaptation for the illness (Visser et al. 2010). It is supposed that spiritual belief can support better emotional functioning, which causes a higher level of quality of life. Additionally, faith can give patients a feeling of an inner peace and strength. It can also help to give a meaning to experience of events and also whole life. Spiritual believes can also lead to decreased feeling of negative emotions like hostility, gives relief and comfort. It can also be a source of hope, comfort, optimism and support for patients, which causes better coping of their illness (Pargament and Ano 2006).

It should be underlined that this research concentrated on religiosity or even church attendance, not spirituality. Although in Polish society (98\% of Roman Catholics), spirituality is most frequently associated with religiosity, this relation is not entirely reciprocal. For example, there may be many patients who consider themselves religious and attend the church, but who are not spiritual and take part in the mass only because of tradition. Such a verification was not performed in this study. The authors plan to continue the study with additional implementation of a psychological measure evaluation spirituality (such as Functional Assessment of Chronic Illness Therapy module Spirituality or Spiritual Attitude and Involvement List-SAIL).

The problem of clear distinguishing between measures of church attendance, religiosity and spirituality is still unsolved. It is possible to evaluate church attendance (as in our study) and spirituality (with psychometric tools such as FACIT-Spirituality or SAIL). The most difficult subject to define is religiosity. Currently, it is usually explained similarly to church attendance and opposed to spirituality.

In conclusion, it should be underlined that religiosity has a significant and complex impact on quality of life, mostly by coping and cognitive representations of suffering and salvation. Results of quality of life assessment in higher religiosity/church attendance group are indicative of the importance of spirituality for the adaptation to chronic illness. In spite of more intensive pain, this group of patients was able to function better and declared more activity in the context of work, efficiency and consequently a better global quality of life. In spite of lower values in the sphere of emotional, social and cognitive components of quality of life, the general quality of their health was good and rose to $78-79 \%$ of maximum value after NCPB. We may attempt to hypothesise that experience of pain despite of its increased intensity and strong emotional burden gave patients a perception of being closer to God.

Open Access This article is distributed under the terms of the Creative Commons Attribution Noncommercial License which permits any noncommercial use, distribution, and reproduction in any medium, provided the original author(s) and source are credited.

\section{References}

Ballantyne, J. C. (2006). Opioids for chronic nonterminal pain. Southern Medical Journal, 99(11), $1245-1255$.

Basinski, A., Stefaniak, T., Vingerhoets, A., Makarewicz, W., Kaska, L., Stanek, A., et al. (2005). Effect of NCPB and VSPL on pain and quality of life in chronic pancreatitis patients. World Journal of Gastroenterology: WJG, 11(32), 5010-5014.

Boelens, P. A., Reeves, R. R., Replogle, W. H., \& Koenig, H. G. (2009). A randomized trial of the effect of prayer on depression and anxiety. International Journal of Psychiatry in Medicine, 39(4), 377-392. 
Bush, E. G., Rye, M. S., Brant, C. R., Emery, E., Pargament, K. I., \& Riessinger, C. A. (1999). Religious coping with chronic pain. Applied Psychophysiology and Biofeedback, 24(4), 249-260.

Bussing, A., Michalsen, A., Balzat, H. J., Grunther, R. A., Ostermann, T., Neugebauer, E. A. et al. (2009). Are spirituality and religiosity resources for patients with chronic pain conditions? Pain Medicine (Malden, Mass.), 10(2), 327-339.

Giovagnoli, A. R., Meneses, R. F., \& da Silva, A. M. (2006). The contribution of spirituality to quality of life in focal epilepsy. Epilepsy \& Behavior: E\&B, 9(1), 133-139.

Harrison, M. O., Edwards, C. L., Koenig, H. G., Bosworth, H. B., Decastro, L., \& Wood, M. (2005). Religiosity/spirituality and pain in patients with sickle cell disease. The Journal of Nervous and Mental Disease, 193(4), 250-257.

Hill, P. C., \& Pargament, K. I. (2003). Advances in the conceptualization and measurement of religion and spirituality. implications for physical and mental health research. The American Psychologist, 58(1), 64-74.

King, M. B., \& Koenig, H. G. (2009). Conceptualising spirituality for medical research and health service provision. BMC Health Services Research, 9, 116.

Koenig, H. G. (2009). Research on religion, spirituality, and mental health: A review. Canadian Journal of Psychiatry.Revue Canadienne De Psychiatrie, 54(5), 283-291.

Makarewicz, W., Stefaniak, T., Kossakowska, M., Basinski, A., Suchorzewski, M., Stanek, A., et al. (2003). Quality of life improvement after videothoracoscopic splanchnicectomy in chronic pancreatitis patients: Case control study. World Journal of Surgery, 27(8), 906-911.

McBride, J. L., Arthur, G., Brooks, R., \& Pilkington, L. (1998). The relationship between a patient's spirituality and health experiences. Family Medicine, 30(2), 122-126.

McCarberg, B. H., \& Billington, R. (2006). Consequences of neuropathic pain: Quality-of-life issues and associated costs. The American Journal of Managed Care, 12(9 Suppl), S263-S268.

Moreira-Almeida, A., Neto, F. L., \& Koenig, H. G. (2006). Religiousness and mental health: A review. Revista Brasileira De Psiquiatria (Sao Paulo, Brazil: 1999), 28(3), 242-250.

Nishimori, M., Kulich, R. J., Carwood, C. M., Okoye, V., Kalso, E., \& Ballantyne, J. C. (2006). Successful and unsuccessful outcomes with long-term opioid therapy: A survey of physicians' opinions. Journal of Palliative Medicine, 9(1), 50-56.

Pargament, K. I., \& Ano, G. G. (2006). Spiritual resources and struggles in coping with medical illness. Southern Medical Journal, 99(10), 1161-1162.

Ruetsch, C. (2010). Empirical view of opioid dependence. Journal of Managed Care Pharmacy: JMCP, 16(1 Suppl B), S9-13.

Seeman, T. E., Dubin, L. F., \& Seeman, M. (2003). Religiosity/spirituality and health. A critical review of the evidence for biological pathways. The American Psychologist, 58(1), 53-63.

Sloan, R. P., Bagiella, E., \& Powell, T. (1999). Religion, spirituality, and medicine. Lancet, 353(9153), 664-667.

Stefaniak, T., Basinski, A., Vingerhoets, A., Makarewicz, W., Connor, S., Kaska, L., et al. (2005). A comparison of two invasive techniques in the management of intractable pain due to inoperable pancreatic cancer: Neurolytic celiac plexus block and videothoracoscopic splanchnicectomy. European Journal of Surgical Oncology: The Journal of the European Society of Surgical Oncology and the British Association of Surgical Oncology, 31(7), 768-773.

Stefaniak, T., Vingerhoets, A., Makarewicz, W., Kaska, L., Kobiela, J., Kwiecinska, B., et al. (2008). Opioid use determines success of videothoracoscopic splanchnicectomy in chronic pancreatic pain patients. Langenbeck's Archives of Surgery/Deutsche Gesellschaft Fur Chirurgie, 393(2), 213-218.

Tarakeshwar, N., Vanderwerker, L. C., Paulk, E., Pearce, M. J., Kasl, S. V., \& Prigerson, H. G. (2006). Religious coping is associated with the quality of life of patients with advanced cancer. Journal of Palliative Medicine, 9(3), 646-657.

Visser, A., Garssen, B., \& Vingerhoets, A. (2010). Spirituality and well-being in cancer patients: A review. Psycho-Oncology, 19(6), 565-572.

Weaver, A. J., \& Koenig, H. G. (2006). Religion, spirituality, and their relevance to medicine: An update. American Family Physician, 73(8), 1336-1337.

Yates, J. W., Chalmer, B. J., St James, P., Follansbee, M., \& McKegney, F. P. (1981). Religion in patients with advanced cancer. Medical and Pediatric Oncology, 9(2), 121-128. 